Original Research Paper

\title{
Sosialisasi Pemahaman Budaya 5R (Ringkas, Rapi, Resik, Rawat, Dan Rajin) di Pt Narmada
}

\author{
Aini $^{1}$, Made Sriasih 2 \\ ${ }^{1}$ Program Studi DIII Teknologi Laboratorium Medis Politeknik Medica Farma Husada Mataram \\ ${ }^{2}$ Magister Manajemen Sumber Daya Peternakan Universitas Mataram
}

DOI: $10.29303 /$ ipmpi.v3i1.1252

Sitasi:. Aini., \& Sriasih, M. (2021). Sosialisasi Pemahaman Budaya 5R (Ringkas, Rapi, Resik, Rawat, Dan Rajin) di Pt Narmada. Jurnal Pengabdian Magister Pendidikan IPA 4(4)

Article history

Received: 1 November 2021

Revised: 30 November 2021

Accepted: 15 November 2021

*Corresponding Author:

Aini,

Program Studi DIII Teknologi

Laboratorium Medis

Politeknik Medica Farma

Husada Mataram.

ainie.mfh@gmail.com

\section{Pendahuluan}

Perubahan dunia industri semakin cepat, semakin banyak pula tuntutan kerja yang diinginkan perusahaan. Untuk mendukung pekerjaan agar dapat dilakukan lebih mudah dan lebih nyaman, salah satu yang harus dibangun adalah budaya kerja. Budaya kerja di perusahaan perlu diciptakan dan dibutuhkan untuk perkembangan perusahaan dimasa yang akan datang dalam menghadapi tantangan di dunia

\begin{abstract}
Kemajuan dunia industri menuntut pekerjaan agar dapat dilakukan lebih mudah cepat dan efisien. Satu prinsip yang harus dibangun untuk mencapai tujuan tersebut adalah memananamkan budaya kerja. Budaya kerja yang banyak diaplikasikan di dunia yaitu 5R (Ringkas, Rapi, Resik, Rawat dan Rajin). Budaya kerja /Sistem 5R menjadi sangat perlu untuk menghindari ketidakteraturan penempatan tools dan sarana lain di tempat kerja, khususnya industri. Tujuan dari pengabdian ini adalah untuk memberikan pemahaman tentang pengetahuan 5R terhadap seluruh karyawan di PT Narmada. PT Narmada merupakan salah satu industri menengah di provinsi Nusa Tengara Barat (NTB) yang bergerak dalam bidang produksi. Kegiatan ini dilakukan dalam bentuk sosialisasi dengan partisipan sejumlah 484 orang karyawan. Indikator keberhasilan dari kegiatan ini adalah evaluasi yang diberikan sebelum sosialisasi dalam bentuk pretest dan setelah sosialisasi dalam bentuk posttest. Indikator pemahaman digunakan nilai posttest minimal 60 . Hasil evaluasi posttest diketahui bahwa sebaran soliasisasi adalah $100 \%$ karyawan sudah memperoleh sosialisasi dan berdasarkan nilai posttest diperoleh pemahaman adalah $90 \%$ dengan nilai diatas 60 . Hasil evaluasi bahwa dari 484 karyawan yang mengikuti sosialisasi tingkat pengetahuan dan pemahaman karyawan terhadap program $5 \mathrm{R}$ meningkat sebesar $70 \%$ dari $20 \%$ ke $90 \%$.
\end{abstract}

Keywords: Pemahaman 5R, Budaya 5R, Ringkas, Rapi. Resik, Rawat, Rajin industri (Bangun 2012).

Salah satu budaya kerja dari jepang yaitu $5 S$ yang terdiri dari Seiri, Seiton, Seiso, Seiketsu dan Shitsuke. Budaya Kerja $5 S$ diartikan ke dalam bahasa Indonesia menjadi 5R yaitu: Ringkas, Rapi, Resik, Rawat dan Rajin. Sistem 5R menjadi sangat perlu karena terjadi ketidakteraturan penempatan tools dan sarana lain di tempat Kerja khususnya pada industri yang mempunyai banyak unit karyawan(Kartika and Hastuti 2011) . Program $5 R$ diharapkan dapat menghilangkan 
atau meminimalkan pemborosan yang ada sehingga terjadi peningkatan produktifitas dan efektivitas dari perusahaan (Rachmawati et al. 2018).

Metode 5R merupakan tahap untuk mengatur kondisi tempat kerja yang berdampak terhadap efektifitas kerja, efisiensi, produktifitas dan keselamatan kerja. Salah satu cara menciptakan suasana kerja yang nyaman adalah perusahaan menerapkan sikap kerja 5R (Nusannas 2018).Lingkungan kerja yang sebelumnya kurang nyaman bagi pekerja dapat diperbaiki dan disusun dengan program $5 \mathrm{R}$, dan karyawan memiliki budaya kerja baik, sehingga kualitas produk yang dihasilkan sesuai standar perusahaan dan internasional ( De Felice et al., 2015) Muara akhir dari implementasi $5 R$ adalah menuju world class manufacturing.

Kebersihan dan efisiensi di lingkungan kerja merupakan kendala yang dihadapi PT Narmada. Manajemen PT Narmada dan tim pengabdi sepakat untuk mengadakan sosialisasi bagi seluruh karyawan tentang program $5 \mathrm{R}$ pada PT Narmada. Sosialisasi ini merupakan salah satu strategi yang dibutuhkan untuk meningkatkan kebersihan dan efisiensi pada lingkungan kerja.

\section{Metode}

Kegiatan pengabdian masyarakat ini dilakukan dengan metode ceramah kepada seluruh karyawan. Dari kegiatan pengabdian diharapkan semua karyawan (100\%) mendapat pemahaman. Setelah pemberian materi pre test lalu pemberian materi melalui ceramah. Pada tahap akhir untuk mengukur materi yang diberikan melalui kemudian diberikan post test (Meylani and Suharsono 2019). Kegiatan ini dilaksanakan pada tanggal Februari 2021. Kegiatan ini dilaksanakan selama 3 (23-25 Februari 2021). meliputi:

Susunana tata pelaksanaan pengabdian

1. Pemberian pre test tentang 5R

2. Ceramah /sosialisasi

3. Pemberian post test.

4. Praktik Partol ( Gemba)

Tabel 1. Rincian Materi Kegiatan

\begin{tabular}{|l|l|l|l|}
\hline No & $\begin{array}{l}\text { Materi } \\
\text { Kegiatan }\end{array}$ & Penyaji & $\begin{array}{l}\text { Hari I, II, } \\
\text { III }\end{array}$ \\
\hline
\end{tabular}

\begin{tabular}{|l|l|l|l|}
\hline 1 & Pre test & $\begin{array}{l}\text { Tim } \\
\text { Pengabdian }\end{array}$ & 09.00 \\
\hline 2 & $\begin{array}{l}\text { a. Konsep } \\
\text { dan } \\
\text { Langkah } \\
\text { 5R } \\
\text { b. Tujuan } \\
\text { yang akan } \\
\text { dicapai } \\
\text { c. Faktor } \\
\text { Keberhasil } \\
\text { an }\end{array}$ & $\begin{array}{l}\text { Dr. Made } \\
\text { Sriasih }\end{array}$ & $10.00-$ \\
11.00 \\
\hline 3 & $\begin{array}{l}\text { Pemaparan } \\
\text { R2, R2. R3, } \\
\text { R4, R5 }\end{array}$ & Aini, S.Si., & $11.00-$ \\
\hline 4 & \multicolumn{2}{|c|}{ Istirahat } & 12.00 \\
\hline 5 & Post Test & $\begin{array}{l}\text { Tim } \\
\text { Pengabdian }\end{array}$ & $13.00-$ \\
\hline 6 & $\begin{array}{l}\text { Praktik } \\
\text { Patrol( } \\
\text { GEMBA) }\end{array}$ & Seluruh tim & 13.30 \\
\hline
\end{tabular}

\section{Hasil dan Pembahasan}

PT Narmada merupakan salah satu Industri yang memiliki hampir 500 karyawan yang bergerak dalam bidang produksi. Target dari kegiatan ini adalah $100 \%$ karyawan memahami tentang 5R. Motivasi dasar penerapan 5R ini adalah untuk meningkatkan efisiensi di seluruh unit dan karyawan. Tujuan diadakannya pengabdian ini adalah untuk memberikan pemahaman terhadap seluruh karyawan dalam menerapkan 5R sebagai budaya yang akan berimplikasi pada efisiensi atau pengurangan biaya pada proses produksi. Aplikasi penerapan 5R merupakan proses untuk menerapkan penataan dan kebersihan kerja atau keselamatan dan kesehatan kerja secara umum termasuk di lingkungan pabrik dan proses pengolahan. Kondisi tempat kerja mencerminkan perilaku 
seseorang terhadap pekerjaan dan konsep ini merupakan sikap terhadap pekerjaan (Nusannas 2018) . Budaya 5R berasal dari Jepang kemudian dan pemahaman awal yang diberikan yaitu mengenai konsep dan langkah-langkah penerapan 5R tujuan yang akan dicapai dengan aplikasi 5R dan faktor keberhasilan yang dapat menunjang program 5R (Nusannas 2016).

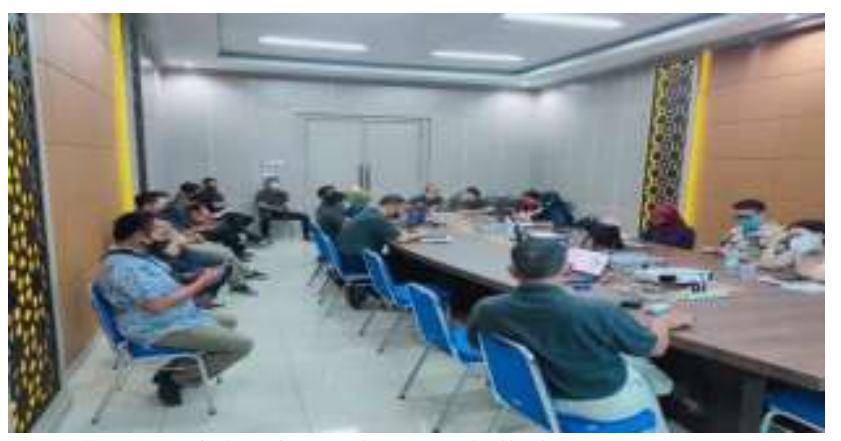

Gambar1. Diskusi awal pengabdi dengan manajemen untuk menganalisa masalah dan stretegi

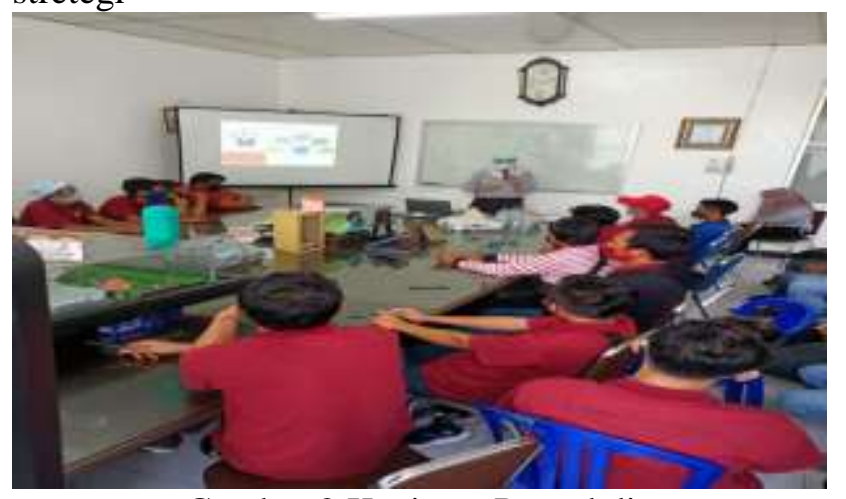

Gambar 2 Kegiatan Pengabdian

Pengabdian ini dilaksanakan 3 hari sehingga tercapai $100 \%$ karyawan mendapatkan pelatihan. Pada tahap awal diberikan pretest selanjutnya diberikan intervensi dalam bentuk sosialisasi lalu dilakukan evaluasi dalam bentuk post test(Iswara, Gunawan, and Dalifa 2018)

Sosialisasi 5R dimulai dengan $\mathrm{R} 1$ ringkas yaitu kegiatan memilih dan mengeluarkan barangbarang yang tidak berguna atau kurang diperlukan dari tempat kerja. Kondisi tampar ringkas itu akan menyebabkan situasi atau ruangan semakin sempit sulit mencari alat yang dibutuhkan alat berlebihan bahkan tidak terkendali barang barang menumpuk tidak teratur dan susah mencari barang (Elyanti 2017).

Rapi atau R2 yaitu kegiatan mengelompokkan barang menyediakan tempat penyimpanan menyimpan pada tempatnya dan memberikan identitas yang jelas agar mudah dikenali. Kondisi yang akan terjadi tanpa rapi yaitu barang lama ditemukan alat kerja tidak diketahui alat kerja rusak tidak diketahui kerapian kerja karyawan tidak diketahui (Rochmanto 2015).

Resik atau R3 adalah merupakan kegiatan membersihkan lingkungan kerja alat kerja dan lainnya sekaligus memeriksa apakah terdapat cacat atau kerusakan kemudian memperbaikinya dan menemukan sumber masalahnya. Kondisi yang akan terjadi tanpa resiko adalah hitam berdebu gelap banyak sawang banyak kotoran bekas tangan percikkan oli percikkan cat banyak tumpahan oli perkakas kerja berceceran tidak terawat dan kerusakan dibiarkan (Rochmanto 2015).

Rawat atau R4 adalah pemantapan dan pembangunan keteraturan dan disiplin dalam implementasi ringkas rapi dan resik. Berikut adalah merupakan kondisi tanpa rawat yaitu kembali bedebu dan banyak sawang. Kembali cover bekas tangan dan percikkan cat ada lagi ceceran oli kembali ada dan ada kerusakan yang dibiarkan. 
Rajin atau R5 adalah pembiasaan dalam melakukan aktivitas penataan tempat kerja yang aman selamat dan produktif. Kondisi yang akan terjadi tanpa rajin adalah hanya sebagian karyawan yang tetap melaksanakan hanya sebagian karyawan yang peduli produk masih cacat atau produk yang sama akar masalahnya belum ditanggulangi.

Evaluasi diberikan dalam bentuk soal yang sama soal pretest dan posttest. Pertanyaan yang diberikan pada evaluasi pretest dan posttest terdiri dari pertanyaan yang bertujuan untuk memudahkan pemahaman pada saat penerapan 5R. Evaluasi yang diberikan pada pretest dan posttest (Meylani and Suharsono 2019). Pengukuran tingkat pemahaman dan kemudahan dalam aplikasi atau pelaksanaan 5R. Pertanyaan yang diberikan memuat kepanjangan 5R, sasaran dari $5 \mathrm{R}$, faktor dalam keberhasilan penerapan 5R, langkah pertama dalam penerapan Ringkas ( $\mathrm{R} 1)$, langkah pertama dalam penerapan rapi (R2), langkah pertama dalam penerapan rawat (R3). Pembuatan soal sudah dibuat sedemikian rupa sehingga mudah dipahami saat pelaksanaan.

Pada akhir setelah post test dilakukan Praktik patrol (Gemba) yang dilakukan pada selesai sosialisasi juga memudahkan penerapan masing-masing personil dilatih untuk melakukan tahapan dari R1 R2 R3 R4 dan R5. Praktik patrol ( Gemba) memberikan kesempatan belajar secara langung mengelopokan barang agar sesuai dengan kaidah R1. R2， R3， R4 dan R5. Gemba adalah suatu jegiatan yang mirip dengan Management by Walking
Around (MBWA), dimana konsep ini merupakan aktivitas yang membutuhkan manajemen berada di front lines untuk mencari tahu waste dan melihat kesempatan untuk dilakukan perbaikan di lantai kerja (shop floor). Konsep Gemba mencakup keterampilan seluruh organisasi, mengajak seluruh karyawan untuk berkontribusi bahkan memberikan pemahaman bahwa perbaikan sekecil apapun dapat menciptkan nilai yang lebih besar dari waktu ke waktu, sehingga konsep ini berfokus pada pencapaian perbaikan terus-menerus.

Secara keseluruhan keberhasilan sosialisasi ini dapat diukur dengan membandingkan nilai pretest dan posttest. Hasil perhitungan nilai untuk pre test memperoleh nilai rata-rata 30 sampai 50 sedangkan nilai postes ratarata 60 sampai 95. Perhitungan berdasarkan prosentase nilai pretest $20 \%$ karyawan mendapatkan nilai diatas 60 dan setelah post test 90 persen karyawan mendapatkan nilai diatas 60 . Tolak ukur untuk nilai kelulusan adalah 60 berdasarkan kesepakatan antara pihak pengabdi dengan industri.

\section{Kesimpulan}

Hasil evaluasi menunjukkan bahwa dari 484 karyawan yang mengikuti sosialisasi tingkat pengetahuan dan pemahaman karyawan terhadap program 5R meningkat sebesar $70 \%$ dari $20 \%$ ke $90 \%$.

\section{Ucapan Terimakasih}

Tim menyampaikan ucapan terima kasih kepada manajemen PT. X, LPPM Universitas 
Mataram dan LPPM Politeknik yang telah memberikan dukungan hingga terlaksananya pengabdian ini

\section{Daftar Pustaka}

Bangun, Wilson. 2012. "Budaya Organisasi: Dampaknya Pada Peningkatan Daya Saing Perusahaan." Jurnal Manajemen Maranatha 8(1):38-49.

Elyanti, NOVA. 2017. "DETERMINAN PERILAKU 5R (RINGKAS, RAPI, RESIK, RAWAT, RAJIN) PADA PERAWAT KELAS III DI RSUD PASAR REBO JAKARTA." Occupational Medicine 53(4):130.

Fabio De Felice, Antonella Petrillo, Stanislao Monfreda. 2015. "It Is Our ' Continuous Improvement System ' Founded in TPM What Is World Class Manufacturing? WCM Is a Mindset Based on a Continuous."

Iswara, Wiwin, Ansyori Gunawan, and Dalifa Dalifa. 2018. "Pengaruh Bahan Ajar Muatan Lokal Mengenal Potensi Bengkulu Terhadap Hasil Belajar Siswa." Jurnal PGSD 11(1):17. doi: 10.33369/pgsd.11.1.1-7.

Kartika, Hayu, and Tri Hastuti. 2011. "Analisa Pengaruh Sikap Kerja 5S Dan Faktor Penghambat Penerapan 5S Terhadap Efektivitas Kerja Departemen Produksi Di Perusahaan Sepatu." Jakarta: Jurnal Ilmiah PASTI V(1):47-54.
Meylani, Vita, and Suharsono Suharsono. 2019. "Pengaruh Pre Test Terhadap Tingkat Pemahaman Mahasiswa Calon Guru Biologi Pada Materi Praktikum Pewarnaan Gram Mata Kuliah Mirobiologi." Bioedusiana 4(2):103-8. doi: 10.34289/277890.

Nusannas, Iman Sidik. 2016. "Implementasi Konsep Budaya 5R ( Ringkas , Rapi , Resik, Rawat Dan Rajin )." Jurnal Ekonomi Dan Bisnis 4(1):93-106.

Nusannas, Iman Sidik. 2018. "Implementasi Konsep Budaya 5R (Ringkas, Rapi, Resik, Rawat Dan Rajin) Sebagai Upaya Meningkatkan Kinerja Perusahaan Dari Sisi Non Keuangan." Eqien: Jurnal Ekonomi Dan Bisnis 3(2):93-106. doi: 10.34308/eqien.v3i2.31.

Rachmawati, Siti, Seviana Rinawati, Iwan Suryadi, and Maria Paskanita. 2018. "Implementation of Cultural 5R (Ringkas, Rapi, Resik, Rawat \& Rajin) With Sni Iso 22000: 2009 Approach and Assessment in Pt.Y Surakarta." Journal of Industrial Hygiene and Occupational Health 2(2):132. doi: 10.21111/jihoh.v2i2.1884.

Rochmanto, Dhani Pura. 2015. "Penerapan Ringkas, Rapi, Resik, Rawat Dan Rajin (5R) Dalam Upaya Pengendalian Kebakaran Di Unit Produksi 2 PT. Kutai Timber Indonesia (KTI)." Artikel Ilmiah Hasil Penelitian Mahasiswa 21-139. 